\title{
ANALISIS FAKTOR KEMACETAN TERHADAP KINERJA LALU LINTAS DI RUAS JALAN JENDERAL BASUKI RAHMAT (STUDI KASUS: MALL BASSURA)
}

\author{
Hafidzsyah Alfiana ${ }^{1}$, Adhi Purnomo ${ }^{2}$ \\ Email:misnike.rurin@gmail.com ${ }^{1}$, apurnomo@unj.ac.id ${ }^{2}$ \\ Prodi D III Transportasi, Fakultas Teknik - Universitas Negeri Jakarta \\ Prodi D III Transportasi, Fakultas Teknik - Universitas Negeri Jakarta
}

\begin{abstract}
Abstrak. Bangunan - bangunan komersial di kawasan Mall Bassura (Jalan Jenderal Basuki Rahmat), telah mengakibatkan kemacetan di kawasan tersebut. Kendaraan memakai badan jalan untuk memarkir kendaraannya, trotoar yang digunakan sebagai tempat dagang oleh pedagang kaki lima, serta posisi pintu masuk/keluar Mall Bassura untuk kendaraan roda empat yang tidak strategis. Hal-hal tersebut di atas yang menyebabkan penulis memilih lokasi di kawasan Mall Bassura (Jalan Jenderal Basuki Rahmat), Jakarta Timur yang merupakan jalur lokal, dimana Jakarta Timur sebagai salah satu kota besar di Daerah Khusus Ibukota Jakarta juga mengalami pertumbuhan kendaraan yang tinggi, hal ini dapat terlihat pada ruas jalan di Jakarta Timur yang sering mengalami kemacetan pada jam-jam sibuk. Tujuan penelitian ini untuk mengetahui kinerja lalu lintas di kawasan tersebut. Metode yang digunakan dalam penelitian ini adalah metode pengamatan langsung di lokasi penelitian dan pengambilan data lapangan berupa data volume parkir, volume pejalan kaki, volume kendaraan masuk/keluar Mall Bassura, volume lalu lintas, serta kinerja ruas jalan. Pengamatan dilakukan pada hari kerja dan hari libur. Hasil analisis kinerja ruas jalan didapatkan bahwa volume lalu lintas yang ada di ruas jalan sekitar Mall Bassura yaitu 32.433 SMP/Jam pada hari kerja dan 22.577 SMP/Jam pada hari libur, dengan indeks tingkat pelayanan berada pada kategori F di hari kerja maupun hari libur. Dengan demikian faktor - faktor kemacetan tersebut di atas mengakibatkan penurunan kapasitas jalan yang berdampak pada kinerja ruas jalan.
\end{abstract}

Kata kunci: : Kemacetan, Kinerja lalu lintas, Kapasitas Jalan, Tingkat Pelayanan

\begin{abstract}
Abstrac, Commercial buildings in the Bassura Mall area (Jalan Jenderal Basuki Rahmat) have resulted in congestion in the area. Vehicles use road bodies to park their vehicles, sidewalks that are used as trading places by street vendors, and the position of the entrance / exit of Bassura Mall for four-wheeled vehicles that is not strategic. These things have caused the author to choose a location in the Bassura Mall area (Jalan Jenderal Basuki Rahmat), East Jakarta which is a local route, where East Jakarta as one of the big cities in the Special Capital Region of Jakarta also experiences high vehicle growth, p. This can be seen on roads in East Jakarta which often experience congestion during rush hour. The purpose of this research is to determine the traffic performance in the area. The method used in this research is direct observation method at the research location and field data collection in the form of parking volume data, pedestrian volume, vehicle volume entering / exiting Mall Bassura, traffic volume, and road performance. Observations were made on weekdays and holidays. The results of the analysis of the performance of the road sections show that the traffic volume on the roads around Mall Bassura is 32,433 SMP / hour on weekdays and 22,577 SMP / hour on holidays, with the service level index being in the F category on weekdays and holidays. Thus, the congestion factors mentioned above have resulted in a decrease in road capacity which has an impact on road performance.
\end{abstract}

Keyword: Congestion, Traffic performance, Road capacity, Service level.

\section{A. PENDAHULUAN}

Peningkatan jumlah kendaraan memberikan dampak terhadap lalu lintas. Permasalahan lalu lintas yang kerap terjadi yakni kemacetan lalu lintas atau berkurangnya suatu kinerja ruas jalan yang dikarenakan beberapa faktor antara lain, tingginya hambatan yang terjadi pada ruas maupun simpang. Banyaknya aktivitas selain lalu lintas yang memakai badan jalan seperti parkir, pusat perbelanjaan dan pejalan kaki yang tidak memiliki trotoar sehingga harus memakai sebagian ruas jalan untuk kegiatan - kegiatan tersebut. Kemacetan lalu lintas pada ruas jalan telah menjadi masalah, terutama di negara berkembang seperti Indonesia.

Salah satu pusat kegiatan komersil yang mempunyai tarikan pergerakan cukup besar di Jakarta Timur adalah Mall Bassura yang terletak di Jalan Jenderal Basuki Rahmat. Selain Mall Bassura juga terdapat aktivitas lainnya berupa adanya Pasar Gembrong, Apartemen Bassura, dan perkampungan warga yang akan menambah tarikan di sekitar kawasan Mall Bassura. Permasalahan yang ada pada Mall Bassura adalah kurangnya lahan parkir yang tersedia yang mana para pengguna kendaraan memarkirkan kendaraannya secara paksa di badan jalan yang sudah jelas terdapat rambu dilarang parkir dan dilarang berhenti, pejalan kaki yang menyeberang tidak pada tempatnya dan tidak memiliki trotoar, serta mobil yang akan keluar masuk Mall Bassura dimana posisi gerbang masuk/keluar jaraknya sangat dekat sehingga menyebabkan antrian kendaraan.

Permasalahan lalu lintas yang timbul akibat aktivitas - aktivitas yang telah disebutkan dan menyebabkan kemacetan ini tentunya merugikan pengguna jalan sehingga membutuhkan penanganan khusus dari Pemerintah Daerah Khusus Ibukota (DKI) Jakarta. Penelitian ini bertujuan untuk menganalisis kinerja lalu lintas di ruas Jalan 
Jenderal Basuki Rahmat khusunya kawasan Mall Bassura. Adapun manfaat dari penelitian ini adalah sebagai bahan masukan dalam upaya penertiban dan penyediaan fasilitas pengguna jalan yang lebih efektif dan efisien.

\section{B. METODE PENELITIAN}

Dalam pembahasan serta beberapa keterangan data yang diperlukkan untuk mengolahnya dalam penulisan karya ilmiah penulis menggunakan data yang dilakukan dengan mengamati secara langsung atas fakta yang terjadi di lapangan jalan Jenderal Basuki Rahmat dengan panjang jalan 300 meter. Dengan izin pelaksanaan dari Suku Dinas Perhubungan Kota Administrasi Jakarta Timur. Pengambilan data ini akan berguna untuk mengevaluasi keberhasilan dari kebijakan yang dikeluarkan oleh Dinas Perhubungan dan Pemerintah. Data diolah dengan menggunakan metode MKJI (Manual Kapasitas Jalan Indonesia) 1997. Hal ini bertujuan untuk mengetahui lebih detail faktor yang mengakibatkan kemacetan lalulintas pada ruas jalan Jenderal Basuki Rahmat, Jakarta Timur.

\section{HASIL DAN PEMBAHASAN}

\section{Karakteristik Fisik Ruas Jalan}

Lokasi koridor jalan di sekitar Mall Bassura atau Jalan Jenderal Basuki Rahmat terletak di Kecamatan Jatinegara Kelurahan Cipinang Besar Selatan, dimana Jalan Jenderal Basuki Rahmat memiliki panjang jalan \pm 3 kilometer, akan tetapi panjang ruas jalan yang diteliti adalah 300 meter. Berdasarkan klasifikasi jalan menurut hierarkinya, Jalan Jenderal Basuki Rahmat termasuk jalan kolektor sekunder. Berdasarkan tipe jalan, Jalan Jenderal Basuki Rahmat merupakan tipe jalan 4 lajur, 2 jalur dengan pembatas median (4/2 T). Kondisi geometrik jalan lokasi studi adalah sebagai berikut :

Tipe jalan

Jalur arah timur
$: 4 / 2 \mathrm{~T}$

: 300 meter

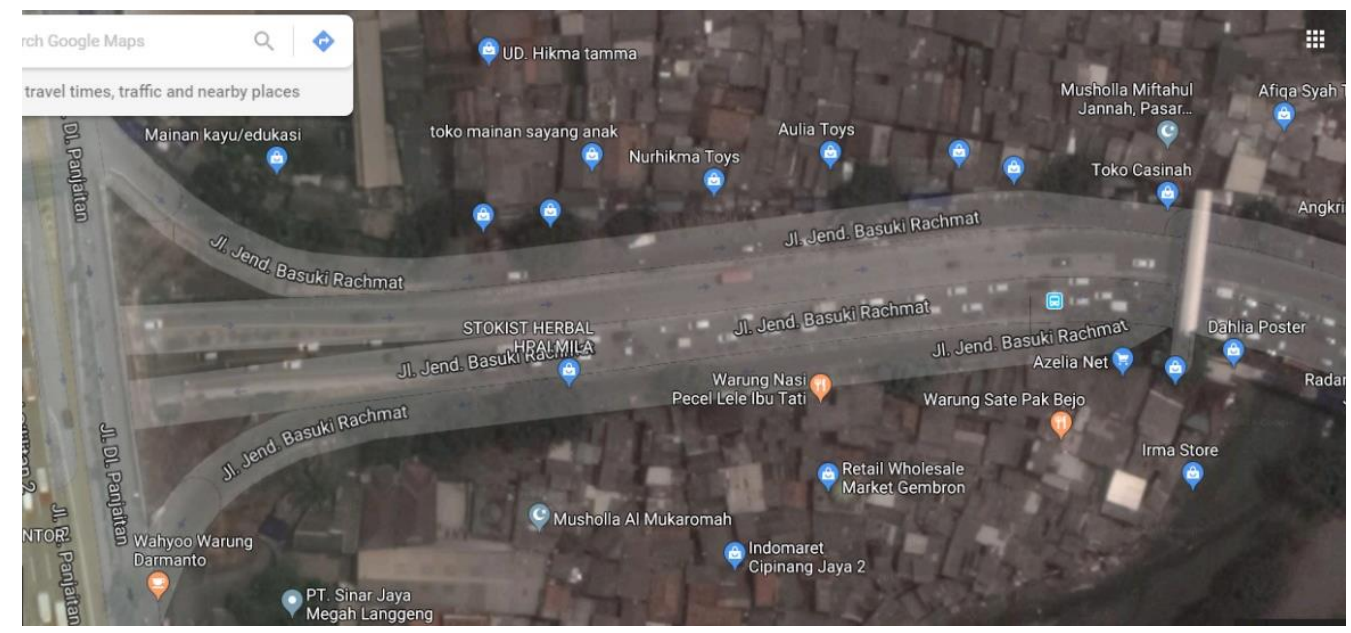

\section{Gambar 1 Peta Lokasi Penelitian}

\section{Karakteristik Penggunaan Lahan}

Pola penggunaan lahan (land use) di ruas jalan ini merupakan kawasan terbangun yang meliputi bangunan permukiman, perdagangan, pertokoan, mall. Zona kegiatan ini sangat menentukan arus lalu lintas yang akan menggunakan fasilitas jalan tersebut, zona kegiatan sangat menentukan asal dan tujuan dari perjalanan dengan kata lain zona kegiatan sangat menentukan dalam bangkitan pergerakan. Ruas jalan pengamatan mempunyai potensi cukup besar dalam membangkitkan pergerakan lalu lintas untuk parkir akibat penggunaan lahan yang dominan komersiil, pejalan kaki, dan mobil yang masuk ke dalam Mall Bassura sehingga mengakibatkan kepadatan dan kemacetan arus lalu lintas terutama pada jam - jam sibuk.

\section{Analisis Parkir di Lokasi Penelitian}

\section{a. Pola Parkir}

Berdasarkan hasil penelitian, di lokasi penelitian rata - rata hanya kendaraan bermotor yang melakukan parkir di badan jalan. Pengunjung yang menggunakan mobil yang ingin memasuki mall lebih memilih memarkirkan kendaraannya di dalam area parkir mall yang telah disediakan, kecuali jika pengunjung tersebut ingin mengunjungi toko di sekitar pasar gembrong maka ia akan memarkirkan mobilnya di sekitar pasar. Berbeda dengan motor yang banyak memarkirkan kendaraannya di bahu jalan sekitar pasar baik itu akan mengunjungi mall atau pasar. Berikut visualisasi pola parkir di badan jalan sekitar Mall Bassura. 
b. Volume Parkir

Volume parkir menyatakan jumlah kendaraan yang termasuk dalam beban parkir (yaitu jumlah kendaraan per periode waktu tertentu, biasanya per hari). Berdasarkan hasil penelitian, jumlah kendaraan yang sudah ada sebelum waktu survei di kawasan Mall Bassura adalah dapat dilihat pada tabel berikut.

c. Rangkuman Karakteristik Parkir di Kawasan Mall Bassura

Karakteristik parkir di lokasi penelitian yang telah dibahas dan dianalisis di halaman sebelumnya dirangkum sebagai berikut.

Pola Parkir

Motor $: 90^{\circ}$ dan $0^{\circ}$ (paralel)

Mobil $\quad: 0^{\circ}$ (paralel)

Truk $\quad: 0^{\circ}$ (paralel)

Tabel 1 Rangkuman Karakteristik Parkir di Kawasan Mall Bassura

\begin{tabular}{|c|c|c|}
\hline Hari & Volume Parkir & SMP/Jam (1,0) \\
\hline Kerja & 237 & 237 \\
\hline Libur & 599 & 599 \\
\hline Jumlah & $\mathbf{8 3 6}$ & $\mathbf{8 3 6}$ \\
\hline
\end{tabular}

Analisis Pejalan Kaki di Lokasi Penelitian

Pengumpulan data diperoleh berdasarkan pengamatan langsung dengan mengumpulkan data - data perhitungan pejalan kaki di lokasi penelitian yang kemudian dilakukan pengolahan dan analisis data. Karakteristik parkir di lokasi penelitian dirangkum sebagai berikut :

Tabel 2 Jumlah Pejalan Kaki di Lokasi Penelitian

\begin{tabular}{|c|c|c|}
\hline Hari & Total Pejalan Kaki & Total SMP/Jam \\
\hline Kerja & 1808 & 906 \\
\hline Libur & 1741 & 872 \\
\hline Jumlah & $\mathbf{3 5 4 9}$ & $\mathbf{1 7 7 8}$ \\
\hline
\end{tabular}

\section{Analisis Kendaraan Masuk/Keluar Mall Bassura}

Pengumpulan data diperoleh berdasarkan pengamatan langsung dengan mengumpulkan data - data perhitungan kendaraan roda empat (mobil) di pintu keluar dan masuk Mall Bassura yang kemudian dilakukan pengolahan dan analisis data.

a. Rangkuman Kendaraan Masuk dan Keluar Mall Bassura

Total kendaraan keluar masuk (mobil) di Mall Bassura yang telah dibahas dan dianalisis di halaman sebelumnya dirangkum sebagai berikut:

Tabel 3 Rangkuman Kendaraan Masuk dan Keluar Mall Bassura

\begin{tabular}{|l|c|c|c|}
\hline Hari & Total Kendaraan Masuk & Total Kendaran Keluar & Total SMP/Jam \\
\hline Kerja & 1334 & 1548 & 2019 \\
\hline Libur & 1372 & 1335 & 1896 \\
\hline Jumlah & $\mathbf{2 7 0 6}$ & $\mathbf{2 8 8 3}$ & $\mathbf{3 9 1 5}$ \\
\hline
\end{tabular}

Rangkuman Faktor - Faktor Kemacetan Lalu Lintas Di Lokasi Penelitian

Faktor - faktor kemacetan lalu lintas di lokasi penelitian telah dianalisis dan dibahas di sub - sub bab sebelumnya. Telah jelas faktor - faktor kemacetan lalu lintas tersebut disebabkan oleh:

1. Parkir di badan jalan (on street parking)

2. Pejalan kaki

3. Kendaraan yang keluar masuk Mall Bassura.

Faktor - faktor ini kemudian akan menjadi hambatan samping pada kinerja lalu lintas di kawasan Mall Bassura.

\section{Analisis Kinerja Lalu Lintas Ruas Jalan Lokasi Penelitian}

a. Analisis Volume Lalu Lintas 
Volume lalu lintas merupakan jumlah kendaraan yang melewati suatu titik tertentu dari satu segmen/ruas jalan selama waktu tertentu. Jenis volume yang digunakan adalah volume jam puncak. Data volume kendaraan diperoleh dari hasil survei lapangan yang dibuthkan untuk mengetahui derajat kejenuhan kendaraan di lokasi penelitian. Klasifikasi kendaraan yang diteliti telah dijelaskan pada tabel 2.1. Hasil dari penelitian volume kendaraan adalah sebagai berikut :

Tabel 4 Total Volume Lalu Lintas Di Ruas Jalan Basuki Rahmat

\begin{tabular}{|l|c|}
\hline \multicolumn{1}{|c|}{ Hari } & Total (SMP) \\
\hline Kerja & 32433 \\
\hline Libur & 22577 \\
\hline Jumlah & $\mathbf{5 5 0 1 0}$ \\
\hline Rata - rata & $\mathbf{2 7 5 0 5}$ \\
\hline
\end{tabular}

Berdasarkan tabel di atas menjelaskan bahwa volume lalu lintas ruas Jalan Jenderal Basuki Rahmat arah timur pada hari kerja lebih banyak dibandingkan hari libur. Hal ini membuktikan bahwa aktivitas di kawasan Mall Bassura pada hari kerja cukup padat dan ramai, dimulai dari aktivitas perdagangan, pemukiman, dan pusat perbelanjaan yang merupakan faktor penarik manusia/orang untuk berkunjung. Banyaknya pengunjung Mall Bassura dan bangunan komersial lainnya membuat volume lalu lintas di ruas jalan tersebut meningkat pada hari kerja, tidak tersedianya lahan parkir yang memadai, pejalan kaki yang tidak memiliki trotoar, serta pintu masuk dan keluar Mall Bassura untuk kendaraan roda empat yang tidak teratur. Bila hal ini dibiarkan begitu saja maka akan menjadi magnet terjadinya kemacetan lalu lintas.

\section{Analisis Hambatan Samping}

Hambatan samping adalah dampak terhadap kinerja lalu lintas yang berasal dari aktivitas samping segmen jalan. Hambatan samping ruas Jalan Jenderal Basuki Rahmat sekitar Mall Bassura adalah parkir di badan jalan (on street parking), pejalan kaki, dan kendaraan yang keluar masuk Mall Bassura. Aktifitas - aktifitas tersebut seringkali membuat ruas jalan sekitar Mall Bassura menjadi macet. Berdasarkan hasil analisis perhitungan kelas hambatan samping pada lokasi penelitian maka diperoleh kelas hambatan samping sebagai berikut:

Tabel 5 Hasil Analisis Perhitungan Kelas Hambatan Samping Pada Lokasi Penelitian Maka Diperoleh Kelas Hambatan Samping

\begin{tabular}{|c|c|c|c|c|c|c|c|}
\hline \multirow[b]{2}{*}{ No. } & \multirow[b]{2}{*}{ Hari } & \multicolumn{3}{|c|}{$\begin{array}{c}\begin{array}{c}\text { Frekuensi Bobot Kejadian Maksimal } \\
\text { (SMP/Jam) }\end{array}\end{array}$} & \multirow[b]{2}{*}{ Total } & \multirow{2}{*}{$\begin{array}{c}\text { mlah Gangguan } \\
\text { Per } 200 \text { meter } \\
\text { per arah }\end{array}$} & \multirow{2}{*}{$\begin{array}{c}\text { Kelas } \\
\text { Hambatan } \\
\text { Samping }\end{array}$} \\
\hline & & Parkir & $\begin{array}{c}\text { Pejalan } \\
\text { Kaki }\end{array}$ & $\begin{array}{l}\text { Kendaraan } \\
\text { Keluar/Masuk }\end{array}$ & & & \\
\hline 1. & Kerja & 237 & 906 & 2019 & 3162 & $>900$ & Sangat Tinggi \\
\hline 2. & Libur & 599 & 872 & 1896 & 3367 & $>900$ & Sangat Tinggi \\
\hline
\end{tabular}

Dari tabel di atas memperlihatkan bahwa frekuensi bobot kejadian terbesar terjadi di hari libur dengan total keseluruhan sebesar 3367 gangguan per 200 meter. Hal ini disebabkan karena fungsi lahan yang ada pada jalan tersebut dimana penggunaan lahannya didominasi pusat perdagangan sehinggan mempengaruhi aktivitas kendaraan baik yang parkir berhenti maupun pejalan kaki di sisi ruas jalan. 


\section{Kecepatan Kendaraan}

Berdasarkan hasil pengamatan kecepatan kendaraan maka diperoleh kecepatan rata - rata total MC (Motorcycle), LV (Light Vehicle), HV (High Vehicle). Adapun rekapitulasi kecepatan rata - rata kendaraan pada jam puncak adalah sebagai berikut:

Tabel 6 Rekapitulasi Kecepatan Rata - Rata Kendaraan Pada Jam Puncak

\begin{tabular}{|c|c|c|c|c|c|}
\hline Hari & $\begin{array}{c}\text { Jarak (d) } \\
\quad(\mathrm{km})\end{array}$ & $\begin{array}{c}\text { aktu Tempuh } \\
(\mathbf{t}) \\
(\operatorname{detik})\end{array}$ & $\begin{array}{c}\text { Waktu Tempuh (t) (jam) } \\
\text { Waktu Tempuh } \\
\text { (detik)/3600 }\end{array}$ & $\begin{array}{c}\text { Kecepatan } \\
\text { Rata - rata } \\
(\mathrm{V}) \\
(\mathrm{Km} / \mathrm{jam}) \\
\mathrm{d} / \mathbf{t}\end{array}$ & $\begin{array}{c}\text { Kecepatan } \\
\text { Minimum } \\
\text { Kolektor } \\
\text { Sekunder } \\
(\mathbf{K m} / \mathbf{j a m})\end{array}$ \\
\hline \multicolumn{6}{|c|}{ MC (Motorcycle) } \\
\hline Kerja & 0,3 & 47 & 0,0131 & 22,90 & 40 \\
\hline Libur & 0,3 & 42 & 0,0117 & 25,64 & 40 \\
\hline \multicolumn{6}{|c|}{ LV (Light Vehicle) } \\
\hline Kerja & 0,3 & 81 & 0,0225 & 13,33 & 40 \\
\hline Libur & 0,3 & 74 & 0,0205 & 14,63 & 40 \\
\hline \multicolumn{6}{|c|}{ HV (High Vehicle) } \\
\hline Kerja & 0,3 & 83 & 0,0231 & 12,99 & 40 \\
\hline Libur & 0,3 & 76 & 0,0211 & 14,22 & 40 \\
\hline
\end{tabular}

\section{Analisis Kapasitas Lalu Lintas}

Pada penelitian ini, nilai kapasitas dasar ruas jalan sesuai dengan tipe jalan yang ditinjau, sedangkan kapasitas terkoreksi disesuaikan dengan kondisi geometrik jalan dan lingkungan sekitarnya. Adapun nilai kapasitas yang diperoleh pada masing - masing segmen ruas jalan lokasi penelitian dapat dilihat pada tabel berikut:

\section{Tabel 7 Nilai Kapasitas Yang Diperoleh Pada Masing - Masing Segmen Ruas Jalan Lokasi}

\begin{tabular}{|c|c|c|c|}
\hline No. & Parameter & Kondisi & Nilai \\
\hline 1. & Kapasitas Dasar (SMP/Jam) & $4 / 2 \mathrm{~T}$ & 1.650 \\
\hline 2. & Faktor Penyesuaian Lebar Jalan & $5,6 \mathrm{~m}$ & 1,08 \\
\hline 3. & $\begin{array}{c}\text { Faktor Penyesuaian Kapasitas } \\
\text { Pemisah Arah }\end{array}$ & $50-50$ & 1,00 \\
\hline 4. & $\begin{array}{c}\text { Samping } \\
\text { Saktor Penyesuaian Hambatan }\end{array}$ & & 0,84 \\
& $\begin{array}{c}\text { ST } \\
\end{array}$ & & 1,00 \\
\hline 5. & Kator Penyesuaian Ukuran Kota & $1,0-3,0$ Juta & $\mathbf{1 4 9 6 , 8 8}$ \\
\hline \multicolumn{2}{|c|}{ Kapasitas (C) SMP/Jam } \\
\hline
\end{tabular}

Dari tabel di atas menunjukkan bahwa kapasitas ruas jalan sekitar Mall Bassura adalah 1496,88 SMP/Jam. Analisis Kepadatan Lalu Lintas

Kepadatan lalu lintas adalah ukuran atau volume kendaraan yang melewati jalan di daerah tertentu dengan arus kendaraan yang bervariasi di saat jam - jam tertentu dinyatakan dalam per jam per kilometer (SMP/km). 
Melihat hubungan antara arus, kecepatan, dan kepadatan, maka diperoleh nilai kepadatan untuk hari kerja dan hari libur yang dipengaruhi oleh parkir di badan jalan (on street parking), pejalan kaki, dan kendaraan yang keluar masuk Mall Bassura dapat dilihat pada tabel berikut:

Tabel 8 Nilai Kepadatan Untuk Hari Kerja Dan Hari Libur Yang Dipengaruhi Oleh Parkir Di Badan Jalan (On Street Parking), Pejalan Kaki, Dan Kendaraan Yang Keluar Masuk Mall Bassura

\begin{tabular}{|l|c|c|c|c|}
\hline No. & Hari & $\begin{array}{c}\text { Volume Lalu Lintas } \\
\text { (SMP/Jam) }\end{array}$ & $\begin{array}{c}\text { Kecepatan } \\
(\mathbf{K m} / \mathbf{J a m})\end{array}$ & $\begin{array}{c}\text { Kepadatan } \\
(\mathbf{K m} / \mathbf{J a m})\end{array}$ \\
\hline 1. & Kerja & 32433 & 16,40 & 1977,62 \\
\hline 2. & Libur & 22577 & 18,16 & 1243,22 \\
\hline
\end{tabular}

\section{Analisis Derajat Kejenuhan}

Derajat kejenuhan digunakan sebagai faktor utama dalam penentuan tingkat kinerja simpang dan segmen jalan, nilai derajat kejenuhan akan menunjukkan apakah segmen jalan tersebut mempunyai masalah kapasitas yang baik atau tidak. Berdasarkan hasil analisis volume lalu lintas dan kapasitas ruas jalan maka diperoleh nilai derajat kejenuhan (DJ) pada volume maksimum masing - masing ruas jalan dapat dilihat pada tabel berikut:

Tabel 9 Nilai Derajat Kejenuhan (DJ) Pada Volume Maksimum Masing - Masing Ruas Jalan

\begin{tabular}{|l|c|c|c|c|}
\hline No. & Hari & $\begin{array}{c}\text { Volume Lalu Lintas } \\
\text { (SMP/Jam) }\end{array}$ & $\begin{array}{c}\text { Kapasitas } \\
\text { (SMP/Jam) }\end{array}$ & $\begin{array}{c}\text { Derajat } \\
\text { Kejenuhan } \\
\text { (DJ) }\end{array}$ \\
\hline 1. & Kerja & 32433 & 1496,88 & 8,62 \\
\hline 2. & Libur & 22577 & 1496,88 & 6,89 \\
\hline
\end{tabular}

Dari tabel di atas menunjukkan nilai derajat kejenuhan pada Jalan Jenderal Basuki Rahmat pada hari kerja adalah 21,66 dan pada hari libur adalah 15,08 dengan kapasitas hanya 1496,88 SMP/Jam. Itu berarti derajat kejenu3han pada hari kerja dan hari libur adalah $>1$ dimana kondisi lalu lintas mengalami kemacetan panjang, kecepatan rendah, dan volume lalu lintas di atas kapasitas.

\section{Analisis Faktor Kemacetan Lalu Lintas Terhadap Kinerja Lalu Lintas}

Tingkat pelayanan suatu ruas jalan ditentukan oleh besaran nilai derajat kejenuhan (DJ) berdasarkan indeks tingkat pelayanan (ITP) jalan. Berdasarkan nilai derajat kejenuhan pada kondisi volume maksimum pada jam puncak, maka dapat ditentukan tingkat pelayanan untuk titik pengamatan ruas jalan sekitar Mall Bassura dapat dilihat pada tabel berikut:

Tabel 10 Tingkat Pelayanan Untuk Titik Pengamatan Ruas Jalan Sekitar Mall Bassura

\begin{tabular}{|c|c|c|c|c|c|}
\hline No. & Hari & $\begin{array}{c}\text { Derajat } \\
\text { Kejenuhan } \\
\text { (V/C) }\end{array}$ & $\begin{array}{l}\text { Kecepatan } \\
(\mathbf{K m} / \mathbf{J a m})\end{array}$ & $\begin{array}{l}\text { Tingkat } \\
\text { Pelayanan }\end{array}$ & Kondisi Lalu Lintas \\
\hline 1. & Kerja & 8,62 & 16,40 & $\mathrm{~F}$ & \multirow{2}{*}{$\begin{array}{l}\text { Is yang terhambat, } \\
\text { kecepatan rendah volume } \\
\text { di atas kapasitas, sering } \\
\text { terjadi kemacetan pada } \\
\text { waktu yang cukup lama }\end{array}$} \\
\hline 2. & Libur & 6,89 & 18,16 & $\mathrm{~F}$ & \\
\hline
\end{tabular}

Berdasarkan hasil perhitungan dan analisis di atas terlihat bahwa aktifitas - aktifitas yang menyebabkan kemacetan memiliki dampak negatif terhadap tingkat pelayanan jalan. Dampak negatif tersebut adalah ruas Jalan Jenderal Basuki Rahmat sekitar Mall Bassura memiliki rasio terhadap kapasitas jalan atau derajat kejenuhan lebih dari 1 baik pada hari kerja maupun hari libur yang berarti lalu lintas sudah sangat padat. Kecepatan pada lokasi penelitian lebih rendah dari $40 \mathrm{Km} / \mathrm{Jam}$. Hal ini disebabkan karena pengaruh hambatan samping dan penggunaan lahan disekitarnya. Penggunaan lahan di ruas jalan sekitar Mall Bassura sangat beragam, mulai dari aktivitas perdagangan, permukiman, serta apartemen sehingga jumlah kendaraan tiap hari yang melewati ruas jalan tersebut meningkat.

Banyaknya bangunan komersial yang ada di lokasi penelitian yang merupakan faktor penarik bagi penduduk untuk berkunjung, namun kebanyakan dari pemilik bangunan yang ada di koridor jalan tersebut tidak menyediakan tempat parkir khusus untuk para pengunjung sehingga banyak pengunjung yang parkir di badan 
jalan. Dan juga lokasi pintu keluar dan masuk Mall Bassura untuk kendaraan roda empat kurang strategis sehingga sering terjadi penumpukkan kendaraan yang menyebabkan kemacetan panjang di ruas jalan tersebut, serta pejalan kaki yang tidak memiliki trotoar sehingga berjalan di badan jalan.

Namun, khususnya kecepatan rata - rata kendaraan pada umumnya berada di bawah standar persyaratan kecepatan untuk jalan kolektor sekunder yaitu $40 \mathrm{Km} / J a m$ dengan nilai ITP sekurang - kurangnya B agar tidak terjadi kemacetan. Akan tetapi, kecepatan dan tingkat pelayanan jalan di lokasi penelitian tidak sesuai standar persyaratan. Hal ini dipengaruhi oleh faktor kondisi arus lalu lintas, kondisi jalan, hambatan samping dan penggunaan lahan sekitar Mall Bassura.

\section{KESIMPULAN}

Berdasarkan hasil pengamatan dan analisis yang telah dilakukan serta dilengkapi dengan data - data pendukung dapat disimpulkan sebagai berikut:

1. Faktor yang menyebabkan kemacetan di ruas jalan sekitar Mall Bassura yang juga merupakan hambatan samping adalah parkir di badan jalan (on street parking), pejalan kaki, dan kendaraan masuk/keluar Mall Bassura. Hambatan samping yang memiliki pengaruh terbesar adalah kendaraan masuk/keluar Mall Bassura.

2. Kapasitas masing - masing ruas jalan yang diambil dari volume lalu lintas tertinggi yakni pada hari kerja di jam 07.00 - 09.00 dengan total 12.915 SMP/Jam dan pada hari libur di jam 16.00 - 18.00 dengan total 10.314 SMP/Jam. Kapasitas jalan pada hari kerja dan hari libur sebesar 1496,88 SMP/Jam.

3. Nilai derajat kejenuhan pada hari kerja sebesar 8,62 dan pada hari libur sebesar 6,89.

4. Tingkat pelayanan jalan berdasarkan perhitungan MKJI 1997 ruas Jalan Jenderal Basuki Rahmat sekitar Mall Bassura adalah F. Berarti arus yang terhambat, kecepatan rendah, volume di atas kapasitas, sering terjadi kemacetan pada waktu yang cukup lama.

\section{E. SARAN}

Saran terhadap analisa dan pembahasan mengenai kinerja lalu lintas di ruas jalan Jendral Basuki Rahmat (Studi kasus mall bassura), yaitu:

1. Pemilik bangunan komersial diwajibkan untuk menyediakan lahan parkir.

2. Lahan bangunan tidak boleh memakai trotoar dan memakan badan jalan sehingga mengganggu aktivitas pejalan kaki dan mengakibatkan hambatan pada kendaraan yang melewati ruas jalan.

3. Melakukan pengaturan manajemen lalu lintas untuk memperlancar pergerakan lalu lintas pada ruas jalan sekitar Mall Bassura

4. Membuat ulang kajian analisis dampak lalu lintas (Andalalin) khususnya pada bagian pintu masuk/keluar Mall Bassura untuk kendaraan roda empat di Lobi Selatan.

5. Memahami dan mengetahui kondisi pergerakan lalu lintas di ruas jalan tersebut sehingga masyarakat lebih taat dan patuh lagi pada rambu dan memakai fasilitas yang telah disediakan.

6. Mempercepat proses barang keluar dengan menambah jumlah armada transportasi atau memperbesar ukuran transportasi agar tidak menumpuk di outbound area.

7. Menambah jumlah SDM untuk mempercepat proses barang keluar yang selalu tinggi.

8. Memperhatikan SOP yang ada agar kegiatan berjalan dengan standar yang ada.

9. Memastikan barang yang keluar tidak salah sehingga tidak terjadi pembatalan.

\section{F. DAFTAR PUSTAKA}

Basri, A. 2017. Analisis Dampak Parkir Terhadap Kinerja Lalu Lintas Di Ruas Jalan Sekitar Mall Panakkukang Kota Makasar [skripsi]. Makassar: Fakultas Sains dan Teknologi, UIN Alauddin Makassar.

Direktorat Jenderal Bina Marga Direktorat Bina Jalan Kota (BINKOT). 1997. "Manual Kapasitas Jalan Indonesia (MKJI)". Jakarta.

Edward K. Morlok. 1995. Pengantar Teknik dan Perencanaan Transportasi. Erlangga. Jakarta.

Marunsenge, G.S., Timboeloeng, J.A., dan Elisabeth, L. (2015). Pengaruh Hambatan Samping Terhadap Kinerja Pada Ruas Jalan Panjaitan (Kelenteng Ban Hing Kiong) Dengan Menggunakan Metode MKJI 1997 3:582. media.neliti.com. Diakses 26 Juni 2019.

Ofyar S. Tamin. 2000. Perencanaan dan Permodelan Transportasi. Institut Teknologi Bandung. Bandung.

Suprapto. E. 2005. Analisis Kapasitas Dan Kondisi Ruas Jalan Sragen Palur [tesis]. Surakarta: Program Pascasarjana, Universitas Muhammadiyah Surakarta. 